\title{
Report of the Annual Meeting
}

Rapports annuels de la Société historique du Canada

\section{Origines de l'université dans les institutions médiévales}

Th.-André Audet

Volume 30, numéro 1, 1951

URI : https://id.erudit.org/iderudit/290030ar

DOI : https://doi.org/10.7202/290030ar

Aller au sommaire du numéro

Éditeur(s)

The Canadian Historical Association/La Société historique du Canada

ISSN

0317-0594 (imprimé)

1712-9095 (numérique)

Découvrir la revue

Citer cet article

Audet, T.-A. (1951). Origines de l'université dans les institutions médiévales. Report of the Annual Meeting / Rapports annuels de la Société historique du Canada, 30(1), 22-25. https://doi.org/10.7202/290030ar 


\title{
ORIGINES DE L'UNIVERSITE DANS LES INSTITUTIONS MÉDIÉVALES
}

\author{
Le Père Th.-André Audet, O.P. \\ Université de Montréal
}

BIEN QU'IL n'ait été question que des origines de l'Université de Paris. on persiste à croire que l'antonomase proposée dans le titre de ce rapport n'était pas historiquement illégitime. L'Université, en effet, apparaît à l'historien comme une création typiquement médiévale, l'oeuvre propre des XIIe et XIII'e siècles dans l'histoire universelle de la culture. D'autre part, l'université de Paris, dans ses origines et dans son évolution, permet de retrouver les fondements institutionnels et juridiques de ces écoles corporatives que les médiévaux et nous-mêmes appelons universités.

Ces problèmes d'origine, toutefois, sont ardus en ce qu'ils échappent aux vérifications positives. Aussi bien, la méthode historique impose ici de surmonter les options purement accidentelles de la recherche pour retrouver un point de section vraiment originel et décisif qui puisse capter la fécondité d'une source, là où l'événement coïncide avec l'esprit qui le cause.

La liaison historique de l'université avec l'école épiscopale de Paris et auparavant avec l'école de Laon nous reporte aux premières années du XII e siècle. A ce plan et à ce moment, il apparait qu'est définitivement accompli un transfert des institutions scolaires du moyen âge, signe d'un déplacement plus profond dans l'histoire de la civilisation. Les monastères ont abandonné leurs institutions scolaires, et les chapitres des cathédrales assument seuls désormais de continuer une tradition de culture et d'éducation qui atteindra bientôt les dimensions spirituelles et historiques d'une renaissance. Or. depuis Charlemagne, les écoles monastiques et les écoles capitulaires, nées d'un besoin commun, avaient surmonté ensemble l'effrondrement général de la culture en Occident. En conséquence, en vérifiant que l'université de Paris n'a pas de rapport, ni dans ses institutions ni dans ses origines, avec les écoles monastiques, on atteint ce point de section méthodologique que nous réclamions. C'est une coupure décisive qu'on opére dans l'histoire de la culture médiévale: on a établi une rupture historique et institutionnelle entre la renaissance carolingienne et la renaissance du XIIe siècle.

Dès lors, la recherche historique qui se donne comme objet de retrouver les origines de l'Université dans les institutions médiévales doit s'appliquer à l'interprétation du fait majeur qu'on vient de dégager: le transfert des institutions scolaires des monastères aux cathédrales.

Une thèse séduisante par son modernisme nous est ici proposée, celle d'une ouvrage désormais classique: G. Paré, A. Brunet, $P$. Tremblay, La Renaissance du XII $\mathbf{e}$ siècle. Les écoles et l'enseignement. ${ }^{2}$ Citons un passage particulièrement précis qui nous livre la pensée des auteurs et celle de leur maître, le $\mathrm{P}$. Chenu.

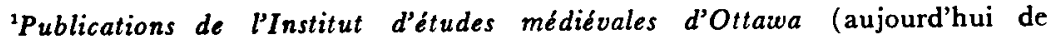
l'Université de Montréal) III, Paris, Ottawa, 1933. 
"Ecoles des monastères, écoles des cathédrales; telle est la classification courante, et certes parfaitement fondée, des centres intellectuels du XIIe siècle. Mais ce ne sont pas là deux régimes parallèles, contemporains d'origine. concurrents par accident sur un sol uniforme; ce sont deux institutions radicalement différentes dans leur esprit, dans leur formule, bientôt dans leur théologie.

'Les écoles monastiques, fruit mûr de la société féodale, ne font que prolonger un état traditionnel, dans une civilisation où déjà les Communes accomplissent leur révolution et ménagent autour de la cathédrale, au milieu de leur turbulence économique et sociale, de nouveaux foyers d'instruction: les écoles dites épiscopales. Les corporations universitaires - celles des clercs ou celles des ordres mendiants - ne feront, au XIIIe siècle, qu'amplifier et institutionnaliser le succès de ces écoles, dans les centres urbains épris de liberté et de progrès, tandis que les écoles monastiques achèveront de mourir de leur conservatisme ...

"Quoique travaillé par la renaissance économique et par les premières effervescences des habitants des villes. le XII siècle vit encore dans son ensemble, sous le régime féodal: économie domaniale et contrat de fief. . . Mais voici que l'horizon s'élargit et que les cadres se rompent. La reprise du trafic méditerranéen, l'essor du commerce continental, le défrichement intensif des terres, l'accroissement rapide de la population, les nouvelles techniques des artisans, la spécialisation du travail, modifient rapidement l'économie des campagnes et des villes. On déserte en masse les domaines du seigneur, chevalier ou abbé, pour former des agglomérations urbaines, où une élite va conquérir, doucement ou violemment, les franchises nécessaires à son travail, à sa richesse, à sa liberté, à sa culture . . . Ainsi voit-on dans la première moitié du XIIe siècle, la puissance urbaine arriver à maturité . . . C'est la révolution communale, effet de la révolution économique à travers l'Europe, des cités italiennes aux villes de la Flandre ou du pays mosan.

"On peut prévoir quels déplacements géographiques des centres culturels vont suivre pareils mouvements sociaux. et il sera aisé d'observer le transfert des écoles et de leur attirail, des monastères aux centres urbains: leur prospérité suivra la prospérité de la "commune" . . . Nous sommes décidément sortis du monastère. L'époque épiscopale réflète en son organisation et en son labeur tous les traits de la commune. Elle est proprement la création du XIIe siècle et de la société nouvelle."

La suite de cette communication s'est attachée à montrer que la thèse qu'on vient de rapporter, malgré un principe valable de méthodr qu'il faut du reste retenir, fait appel à des considérations trop générales et trop hâtives que ni la géographie ni la chronologie ne permettent d'étendre adéquatement à l'évolution institutionnelle des écoles médiévales.

Des dépendances littéraires et des rapports idéologiques peuvent montrer à l'évidence que le $\mathrm{P}$. Chenu et les auteurs de La Renaissance $d u X I I^{\mathrm{e}}$ siècle ont proposé leur théorie dans une référence trop systématique à l'oeuvre d'un grand maître. Henri Pirenne, le prestigieux historien des villes du moyen âge. 
Dans une première position méthodologique, on a critiqué une assimilation trop cavalière de toutes les villes médiévales dans le droit des communes. La commune, à l'origine, est un fait juridique essentiellement limité parmi les libertés urbaines qui, du reste. et particulièrement au XII'e siècle et en France, n'est lié que très accidentellement à quelque revendication de franchise personnelle ou d'autonomie administrative. Les variations profondes de chronologie interdisent au surplus tout nivellement juridique de la commune médiévale. D'autre part, les immenses différences qui séparent géographiquement et politiquement les régions européennes les plus dissemblables maintenaient au moyen âge une hétérogénéité radicale des institutions et de l'évolution des institutions que l'historien doit lui-même maintenir dans ses synthèses.

Cette méthode trop statique qu' on vient de dénoncer prédisposait le $\mathrm{P}$. Chenu et ses disciples à accepter par surcroît les théories économiques de Pirenne Après un bref rappel de la synthèse du maître gantois, on a tenté de montrer que celle-ci, soumise à une domination trop impérialiste des facteurs économiques, n'est plus applicable aux villes françaises ni à la marche de leurs écoles épiscopales vers les institutions universitaires. On s'explique mal le curieux illogisme qui a poussé nos historiens des écoles et de l'enseignement à revendiquer pour les vieilles cités épiscopales toute l'émancipation urbaine que, par ses déterminismes les plus profonds, le système même de Pirenne se doit de leur refuser. Il faut ici résister au mirage des grandes cités flamandes ou des républiques italiennes, où les hypothèses de l'historien belge sont sans doute vérifiables en quelque extension, mais où aussi et précisément il n'y eut jamais d'universités.

On a donc dû rappeler que dans la France du XIIe siècle et dans cette région comprise de la Somme à la Loire, qui fut le pays de presque toutes les plus anciennes communes, on ne trouve guère d'agglomérations marchandes ou industrielles, et que dans l'ensemble la prospérité économique était de source en grande partie agricole. A cette vie économique, les monastères restent associés. De la sorte, on réduit, et considérablement, l'opposition systématique entre féodalité et bourgeoisie qu'on a voulu assigner à l'origine des déplacements institutionnels des écoles monastiques et épiscopales.

En estompant de la sorte les oppositions entre féodalité et bourgeoisie dans le tableau de la vie économique, on offre aussi moins de prise aux interprétations républicaines du droit communal, selon le romantisme d'Augustin Thierry qu'à notre avis la synthèse de Pirenne a assimilé trop copieusement. C'est la troisième influence qu'on a discernée dans la théorie du $\mathrm{P}$. Chenu et qu'on s'est permis de critiquer. Contre les tendances d'une méthode qui nous parait trop abusivement régressive en présumant que les catégories juridiques de notre temps sont toutes réductibles à l'humble matérialité des institutions médiévales, on a rappelé le droit et l'emprise de la coutume dans les moeurs du moyen âge. Cette référence au droit coutumier, qui plonge en pleine féodalité carolingienne, nous permet de retrouver, à côté des associations marchandes - les seules homologuées par certains historiens modernes - toutes les autres ghildes et confréries du haut moyen âge dont les initiatives et même les rites rejoignent sans heurt les premières conjurations communales et bientôt les premières corporations univer- 
sitaires. Aussi bien, quand les dialecticiens et les théologiens de Paris, émigrés des écoles épiscopales voisines ou venus de régions plus lointaines, éprouveront le besoin de solidariser leur force dans une agrégation inédite, ils trouveront sur place et dans les institutions corporatives d'une longue tradition les cadres et l'esprit de leur nouvelle association.

Áinsi, l'Université consacrera juridiquement la promotion des écoles épiscopales, urbaines par définition. Mais une histoire de l'émancipation urbaine asservie à ces déterminismes économiques trop aventureux et trop violents doit renoncer à expliquer les changements profonds où s'opère la plus décisive transformation institutionnelle qui touche l'histoire de la culture au moyen âge. Les facteurs économiques n'ont pas provoqué de métamorphoses brutales des moeurs ou des institutions. L'université de Paris n'entre pas dans l'histoire sous la pression d'une révolte urbaine contre une féodalité décadente.

Du reste, l'histoire des villes françaises, même détachée des synthèses ambitieuses de Pirenne et réduite à des dimensions moins pittoresques, n'explique qu'en partie et que de l'extérieur l'avènement de l'université dans les institutions médiévales et n'explique pas du tout, à notre avis, la rupture historique que nous avons constatée entre les écoles monastiques et les écoles du clergé séculier.

On a donc proposé que l'évolution d'institutions, que le for civil lui-même remet spontanément à la juridiction de l'Eglise, doit chercher sa première explication dans le droit ecclésiastique et dans les catégories de l'histoire religieuse. Dans ce contexte, on discerne nettement une politique antiscolaire des réformes monastiques, mais commandée par un ordre de causes spirituelles et soustraite aux contingences économiques. Le monachisme grec, en effet, aura connu les mêmes évolutions et le même abandon de ses institutions scolaires, et pour les mêmes raisons d'ascèse et de spiritualité. Bien plus, la chronologie même interdirait de dramatiser les changements institutionnels des écoles de monastères aux écoles de cathédrales. Au XIIe siècle, ces régimes scolaires ont cessé d'être contemporains: ils ne sont plus parallèles, encore moins concurrents. Amorcées immédiatement par l'ample réforme grégorienne, la différenciation et même l'opposition institutionnelle des écoles monastiques et des écoles cléricales se durcissent par le droit d'exemption qui soustrait progressivement les abbayes aux juridictions épiscopales. Il n'est pas accidentel que le pape Alexandre III, ancien élève d'Abélard, qui a le plus travaillé pour les libertés monastiques, est celui-là même qui amplifiera les prescriptions de Grégoire VII en matière d'enseignement et étendra l'institution gratuite de la licentia docendi pour les clercs. Sa politique persévérante conduira à la législation universelle du Concile de Latran en 1179. Dans la même tendance historique et juridique, nous verrons au XIIIe siècle les corporations universitaires se réclamer d'un droit d'appel au pape et des sanctions romaines pour résister plus efficacement au droit de prescription des chancelleries épiscopales. 